University of Nebraska - Lincoln

DigitalCommons@University of Nebraska - Lincoln

Publications from USDA-ARS / UNL Faculty

U.S. Department of Agriculture: Agricultural

Research Service, Lincoln, Nebraska

2003

\title{
Understanding the Effect of Rye Chromatin in Bread Wheat
}

\author{
A. M. Kumlay \\ University of Nebraska-Lincoln \\ P. Stephen Baenziger \\ University of Nebraska-Lincoln, pbaenziger1@unl.edu \\ K. S. Gill \\ University of Nebraska-Lincoln \\ D. R. Shelton \\ WheatMarketing Center \\ Robert A. Graybosch \\ USDA-ARS; University of Nebraska-Lincoln, bob.graybosch@ars.usda.gov \\ See next page for additional authors
}

Follow this and additional works at: https://digitalcommons.unl.edu/usdaarsfacpub

Part of the Agricultural Science Commons

Kumlay, A. M.; Baenziger, P. Stephen; Gill, K. S.; Shelton, D. R.; Graybosch, Robert A.; Lukaszewski, A. J.; and Wesenberg, D. M., "Understanding the Effect of Rye Chromatin in Bread Wheat" (2003). Publications from USDA-ARS / UNL Faculty. 906.

https://digitalcommons.unl.edu/usdaarsfacpub/906

This Article is brought to you for free and open access by the U.S. Department of Agriculture: Agricultural Research Service, Lincoln, Nebraska at DigitalCommons@University of Nebraska - Lincoln. It has been accepted for inclusion in Publications from USDA-ARS / UNL Faculty by an authorized administrator of DigitalCommons@University of Nebraska - Lincoln. 


\section{Authors}

A. M. Kumlay, P. Stephen Baenziger, K. S. Gill, D. R. Shelton, Robert A. Graybosch, A. J. Lukaszewski, and D. M. Wesenberg 


\title{
Understanding the Effect of Rye Chromatin in Bread Wheat
}

\author{
A. M. Kumlay, P. S. Baenziger,* K. S. Gill, D. R. Shelton, R. A. Graybosch, \\ A. J. Lukaszewski, and D. M. Wesenberg
}

\begin{abstract}
Most experiments on 1RS translocations in wheat (Triticum aestivum L.) cannot separate the effects of introgressions of rye (Secale cereale $\mathbf{L}$.) chromosome arm from the absence of corresponding wheat chromosome arms. The objective of this research was to determine the contribution of individual wheat and rye group 1 chromosome arms. Five group 1 ditelosomics, six substitutions, and 16 translocations of $1 R$ in wheat were compared with appropriate controls. All ditelosomics were significantly different from controls for 100-kernel weight (100-KW), flour protein content (FP), Mixograph peak time (MT) and tolerance (MTO), and sodium dodecyl sulfate sedimentation (SDSS) volume. Among the long arms, 1DL was the most important for enduse quality and 1AL the least important, ranking even below the 1RL tested. The contribution of all short arms was low. Substitutions of 1R negatively impacted agronomic performance with the long arm being entirely responsible for this effect. Among translocation lines, those with 1RS.1BL had the highest yield and those with 1RS.1DL the lowest. Negative impact of all translocations of 1RS on the enduse quality was far greater than the absence of the corresponding $1 \mathrm{~S}$ arms of wheat. Translocation 1RS.1AL was the least detrimental to quality and 1RS.1DL the most detrimental. Both the source of the rye chromatin and its position in the wheat genome affected agronomic performance and quality. These results suggest that it may be possible to create new translocations of $1 \mathrm{RS}$ in wheat with improved performance. Translocation of $1 \mathrm{RS}$ to $1 \mathrm{AL}$ is preferred from a quality point of view; that to $1 \mathrm{BL}$ appears more beneficial for agronomic performance.
\end{abstract}

I NTROGRESSIONS OF RYE chromatin into wheat through wheat-rye chromosomal substitutions and translocations have increased the genetic diversity of bread wheat cultivars for various characters (Zeller and Hsam, 1984). The chromosomal translocations of the short arm of rye chromosome $1 \mathrm{R}$ to the long arm of wheat group 1 chromosomes are of particular interest to wheat breeders. The $1 \mathrm{RS}$ arm carries genes for resistance to diseases, arachnids, and insects (McIntosh, 1984; Zeller and Hsam, 1984). Translocations of 1RS to the wheat chromosome arms 1AL and 1BL have been the most extensively used because, in addition to the resistance loci, they positively affect agronomic traits including yield performance, yield stability, and wide adaptation (Rajaram et al., 1984; Villarreal et al., 1991; William and Mujeeb-Kazi, 1993; Carver and Rayburn, 1994; Schlegel

A.M. Kumlay, P.S. Baenziger, and K.S. Gill, Dep. of Agronomy and Horticulture, and R.A. Graybosch, USDA-ARS, Univ. of Nebraska, Lincoln, NE 68583; D.R. Shelton, Wheat Marketing Center, 1200 N.W. Naito Parkway, Suite 230, Portland, OR 97209; A.J. Lukaszewski, Dep. of Botany and Plant Science, Univ. of California, Riverside, CA 92521-0124; D.M. Wesenberg, USDA-ARS, Aberdeen, ID 83210. Contribution no. 13724 from the Nebraska Agric. Res. Div. Received 7 June 2002. *Corresponding author (pbaenziger1@unl.edu).

Published in Crop Sci. 43:1643-1651 (2003).

(C) Crop Science Society of America

677 S. Segoe Rd., Madison, WI 53711 USA and Meinel, 1994; Moreno-Sevilla et al., 1995a; McKendry et al., 1996). The 1RS.1BL translocation is one of the most frequently used alien introgressions in wheat breeding programs throughout the world (Braun et al., 1998). It was derived from the Russian cultivars 'Aurora' and 'Kavkaz' (Zeller and Hsam, 1984). The 1RS.1AL translocated wheats derived from 'Amigo' have also been extensively used in wheat breeding programs in the USA (Graybosch, 1995; 2001).

Although the 1RS introgressions have conferred broad adaptation, high yields, and yield stability, they have frequently demonstrated unsatisfactory end-use quality, especially diminished mixing tolerance, dough stickiness, reduced loaf volume, and poor crumb grain when compared with wheats with a standard chromosome constitution (Dhaliwal et al., 1990, Burnett et al., 1995; Lee et al., 1995; Seo et al., 1995). Carver and Rayburn (1995) indicated that the 1RS.1BL translocation lines had, on average, increased grain protein content and decreased dough mixing properties and SDS sedimentation volumes. Moreno-Sevilla et al. (1995b) determined that the 1RS.1BL genotypes from the 'Rawhide' background had a higher protein content, similar mixing time, and lower mixing tolerance than 1B genotypes. Shepherd et al. (1992) indicated that the 1RS.1DL translocation had much weaker dough properties than the equivalent rye arm in a $1 \mathrm{RS} .1 \mathrm{BL}$ translocation in the same background. On the other hand, Graybosch et al. (1993) have shown that the 1RS.1AL translocation was less detrimental to the bread-making quality of wheat than the 1RS.1BL translocation. Consequently, the 1RS.1AL translocation was considered a better way to utilize rye genes in the genetic improvement of wheat (Graybosch et al., 1993).

The quality defects associated with 1RS introgressions in wheat may be a consequence of a change in the protein composition, especially reduced dough glutenin concentration, resulting from the removal, through the substitution by 1RS, of one short arm of a group 1 chromosome of wheat. These arms carry loci-encoding gliadins and low molecular weight glutenins that have a direct effect on end-use quality of wheat. Alternatively, the quality defect may also be a consequence of the presence of rye secalins in these lines (Dhaliwal et al., 1990; Graybosch et al., 1993; Lee et al., 1995), or a combination of both factors. Because the presence of a $1 \mathrm{RS}$ translocation in wheat is concomitant with the absence of the replaced wheat arm, the two effects cannot be easily separated. Minor detrimental effects of the removal of the short arms of wheat group 1 chromo-

\footnotetext{
Abbreviations: FP, flour protein content; GVW, grain volume weight (test weight); GY, grain yield; HD, days to heading; 100-KW, hundredkernel weight; MT, Mixograph peak time; MTO, Mixograph tolerance; SDSS, sodium dodecyl sulfate sedimentation.
} 
somes on the quality parameters were observed in the experiments of Rogers et al. (1990). On the other hand, addition of a rye secalin locus Sec-2 to wheat had no detectable effect on breadmaking quality (Gupta et al., 1989). As Sec-2 is located on rye chromosome $2 \mathrm{RS}$, the substitution of this arm into wheat does not affect the dosage or the composition of the wheat storage protein loci.

The major limitation to studying the effects of 1RS is that, in the standard genetic background of wheat, it does not recombine with the corresponding wheat chromosomes arms. It is therefore impossible to separate the effects of individual chromosome arms and difficult to eliminate the possible genetic drag resulting from the chromosome location of the Glu-1 loci. To address some of these problems, Lukaszewski (1993) physically separated the two arms of the 1RS.1BL translocation and fused them to $1 \mathrm{BS}$ and $1 \mathrm{RL}$ arms, in essence reconstructing complete $1 \mathrm{~B}$ and $1 \mathrm{R}$ chromosomes. The reconstructed chromosome $1 \mathrm{R}$ was then substituted for $1 \mathrm{~A}$ and $1 \mathrm{D}$ by monosomic shift, and complete sets of all three substitutions of the reconstructed $1 \mathrm{R}$ and all six possible compensating centric translocations of $1 \mathrm{RS}$ and $1 \mathrm{RL}$ to group 1 chromosomes of 'Pavon 76' wheat were created (Lukaszewski, 1997). As a by-product of these manipulations, a complete set of ditelosomic lines for group 1 chromosomes in Pavon 76 was also generated. Taken together, these lines permit the separation of the effects of various arms in normal and 1RStranslocated wheat on agronomic and end-use quality, which is the goal of this research.

\section{MATERIALS AND METHODS \\ Origin of Plant Genetic Material}

The tested materials were in the genetic background of Pavon 76, a white spring wheat from the International Maize and Wheat Improvement Center (CIMMYT), Mexico. Various substitutions and translocations were transferred into $\mathrm{Pa}-$ von 76 with at least seven backcrosses completed, or were generated in Pavon 76 itself after a minimum of seven backcrosses. Whenever possible, each disomic wheat-rye substitution or homozygous translocation line was produced with a sister line containing the normal chromosome constitution, to serve as checks in field trials. In almost all cases, at least three original plants with disomic substitutions or three translocation homozygotes with at least three normal sibs were selected and grown for each chromosome construct. Their progenies were bulked for the field trials.

The original translocation chromosome 1RS.1BL for these experiments was taken from wheat cultivar 'Genaro 84', a line of the 'Veery' series from CIMMYT into which it was introduced from 'Kavkaz' (Rajaram et al., 1984). It was transferred to Pavon 76 by a series of backcrosses to $1 \mathrm{~B}$ monosomics. All monosomics for group 1 chromosomes of Pavon 76 were produced by backcrosses to the corresponding monosomics of 'INIA 66' obtained from Dr. R. Pienaar, Univ. of Stellenbosch, Republic of South Africa, with 10 backcrosses completed.

Samples of progenies of Pavon 76 monosomics 1A, 1B, and $1 \mathrm{D}$ and their double monosomics with $1 \mathrm{R}$ were screened cytologically, and plants with telocentrics were selected and grown. Their progenies were screened cytologically, and a complete set of ditelosomic lines was established. Because of severely reduced fertility, the Dt1BS line was not included in this experiment.

A complete chromosome $1 \mathrm{R}$ was identified in a breeding line of wheat E12165 (hence denoted by a subscripted "e") selected at CIMMYT from a triticale $(\times$ Triticosecale Wittmack) $\times$ wheat cross (Lukaszewski, 1993). It was transferred to Pavon 76 by backcrosses and moved by monosomic shift from its original substitution for $1 \mathrm{D}$ to substitutions for $1 \mathrm{~A}$ and $1 \mathrm{~B}$. Once there, this chromosome was translocated by centric breakage-fusion to group 1 chromosomes of Pavon 76 with all six compensating translocations produced (Lukaszewski, 1993, 1997). The origin of chromosome arms in this set of translocations is denoted by a subscripted " $\mathrm{e}$ " for arms of 1R from E12165 and "p" for arms of Pavon 76.

Translocation $1 \mathrm{BS}_{\mathrm{p}} .1 \mathrm{RL}_{\mathrm{e}}$ was used to reconstruct complete chromosomes $1 \mathrm{~B}$ and $1 \mathrm{R}$ from the original centric translocation 1RS.1BL from Genaro-Veery (Lukaszewski 1993, 1997). Reconstructed chromosomes $1 \mathrm{~B}_{\text {rec }}$ and $1 \mathrm{R}_{\mathrm{rec}}$, in effect centric translocations $1 \mathrm{BS}_{\mathrm{p}} \cdot 1 \mathrm{BL}_{\mathrm{v}}$ and $1 \mathrm{RS}_{\mathrm{v}} \cdot 1 \mathrm{RL} \mathrm{L}_{\mathrm{e}}$, were used to generate new centric translocations $1 \mathrm{RS}_{\mathrm{v}} \cdot 1 \mathrm{AL}_{\mathrm{p}}, 1 \mathrm{RS}_{\mathrm{v}} \cdot 1 \mathrm{BL}$, and $1 \mathrm{RS}_{\mathrm{v}} \cdot 1 \mathrm{DL}$, where the subscripted "v" identifies the chromosome arms from the 1RS.1BL translocation of Genaro-Veery, "p" from Pavon 76, and "e" from chromosome 1R from E12165.

During the reconstruction of complete chromosomes $1 \mathrm{R}$ and $1 \mathrm{~B}$ from the centric translocations $1 \mathrm{RS} .1 \mathrm{BL}$ and $1 \mathrm{BS} .1 \mathrm{RL}$, two chromosomes were recovered that must have resulted from noncentric breakage and reciprocal exchange of the short-arm segments distal to the breakpoint. From these chromosomes, the following four wheat-rye translocation chromosomes were produced by centric breakage-fusion and included in this experiment: rye chromosome $1 \mathrm{R}$ with a proximal insert of $1 B S$ on $S\left(1 R_{\text {ins }}\right)$, rye chromosome $1 R$ with a terminal segment of $1 \mathrm{BS}$ on $\mathrm{S}\left(1 \mathrm{BS}_{\text {ins }} .1 \mathrm{RL}\right)$, wheat chromosome $1 \mathrm{~B}$ with a proximal insert of $1 \mathrm{RS}$ on $\mathrm{S}\left(1 \mathrm{~B}_{\text {ins }}\right)$, and wheat chromosome $1 \mathrm{~B}$ with a terminal segment of $1 \mathrm{RS}$ on $\mathrm{S}\left(1 \mathrm{RS}_{\mathrm{ins}} .1 \mathrm{BL}\right)$ (Lukaszewski, 1993, 1997). $1 \mathrm{BS}_{\text {ins }} .1 \mathrm{RL}$ and $1 \mathrm{~B}_{\text {ins }}$ carry all storage protein loci typical of a normal 1BS of Pavon 76 and no Sec-1 from rye; $1 \mathrm{R}_{\text {ins }}$ and $1 \mathrm{RS}_{\text {ins. }}$. $1 \mathrm{BL}$ carry $\mathrm{Sec}-1$ and no storage protein loci from 1BS. Each of these four chromosomes was substituted for normal 1B. Relative lengths of the wheat and rye segments in the short arms of these chromosomes suggested that the original, noncentric breakage was nonsymmetrical. Consequently, depending on the configuration, the translocated chromosomes listed above carried either a deletion of a segment or wheat-rye duplication. For the photographs of the chromosomes in question, see Fig. 2 in Lukaszewski (1997).

Several existing and new centric translocations of the rye $1 \mathrm{RS}$ arm to the long arms of wheat group 1 chromosomes were previously identified or produced in various cytological screenings and experiments and were backcrossed into Pavon 76. These translocations were: $1 \mathrm{RS} .1 \mathrm{AL}$, originally from Amigo (denoted 1RS.1AL $\mathrm{Am}_{\mathrm{Am}}$ ); a new 1RS.1BL, identified among CIMMYT wheat lines selected from triticale $\times$ wheat hybrids (denoted $1 \mathrm{RS} 1 \mathrm{BL}_{\mathrm{cim}}$ from line E12169); 1DS.1RL and 1RS.1DL, selected during the development of disomic addition lines of 'Blanco' rye to a Brazilian wheat line BH1146 (denoted $1 \mathrm{DS} .1 \mathrm{RL}_{\mathrm{bb}}$ and $1 \mathrm{RS} .1 \mathrm{DL}_{\mathrm{bb}}$, respectively); and 1RS.1DL, selected from a hybrid of a 1R(1D) substituted wheat line obtained from Dr. J.P. Gustafson, USDA-ARS, to 'Wheaton' (denoted 1RS.1DL $\mathrm{w}_{\mathrm{w}}$ ).

In an attempt to improve breadmaking quality of hexaploid triticale, the Glu-D1 locus from the long arm of chromosome $1 \mathrm{D}$ was translocated by a combination of centric breakagefusion followed by two rounds of induced homeologous recombination to the long arm of rye chromosome $1 \mathrm{R}$, where 
it replaced rye secalin locus Sec-3 (Lukaszewski and Curtis, 1992). The resulting chromosome $1 \mathrm{R} \cdot 1 \mathrm{D}_{5+10}-2$ was transferred to Pavon 76 by backcrosses, where it substituted for chromosome $1 \mathrm{D}$. By a monosomic shift, chromosome $1 \mathrm{R} .1 \mathrm{D}_{5+10^{-2}}$ was moved to substitute for chromosome 1A. The two substitution lines, 1 R. $1 \mathrm{D}_{5}+10^{-} 2(1 \mathrm{D})$ and $1 \mathrm{R} \cdot 1 \mathrm{D}_{5}+10^{-} 2(1 \mathrm{~A})$, were also included in this experiment. As far as their composition at the storage protein loci is concerned, $1 \mathrm{R} \cdot 1 \mathrm{D}_{5}+10^{-2}(1 \mathrm{D})$ is equivalent to a $1 \mathrm{RS} .1 \mathrm{DL}$ translocation; $1 \mathrm{R} .1 \mathrm{D}_{5}+10^{-2}(1 \mathrm{~A})$ is equivalent to a $1 \mathrm{RS} .1 \mathrm{AL}$ translocation except that it has four doses of the Glu-D1 locus (allele $d$ ) instead of two doses each of Glu-A1 (allele $a$ ) and two doses of Glu-D1 (allele $d$ ). No sibs with normal chromosome constitution were produced for these lines to serve as controls.

Overall, this experiment consisted of five ditelosomic lines, six substitution lines of $1 R$ (three of $1 R_{e}$ and three of $1 R_{r e c}$ ), two substitution lines of $1 \mathrm{R} \cdot 1 \mathrm{D}_{5}+10^{-} 2$, one substitution of $1 \mathrm{~B}_{\text {rec }}$ for $1 \mathrm{~B}$ (in essence, a substitution of $1 \mathrm{BL}_{\mathrm{v}}$ for $1 \mathrm{BL}_{\mathrm{p}}$ ), six centric translocations of $1 \mathrm{R}_{\mathrm{e}}$ to group 1 chromosomes of Pavon 76 plus $1 \mathrm{RS}_{\mathrm{e}} \cdot 1 \mathrm{BL} \mathrm{L}_{\mathrm{v}}$, six centric translocations of $1 \mathrm{R}$ from various sources, four lines with noncentric translocations of $1 \mathrm{RS}$ with $1 \mathrm{BS}$, and 16 control lines with normal chromosome constitution, for a total of 46 lines and Pavon 76. Ditelosomics of Pavon 76 were tested to evaluate the relative contribution of each arm to the agronomic performance and the end-use quality.

\section{Analysis of Agronomic Characteristics}

The five ditelosomic lines and Pavon 76 were planted at Aberdeen, ID, in 1995 and 1996. Because of their reduced vigor and fertility, they were evaluated in a separate trial from the euploid lines. Limited seed precluded replication in each year though there was adequate seed to plant at the normal seeding rate. Each plot consisted of a single 2.44-m row with $0.36 \mathrm{~m}$ between rows. Pavon 76 was used as a control, and to minimize outcrossing each plot was separated by a row of 'Crystal II' barley (Hordeum vulgare L.).

The euploid lines (substitutions, translocations and sib-lines as checks) were planted in Aberdeen, ID (irrigated), in 1995 and 1996, and in Tetonia, ID, (rainfed) locations in 1996 in a randomized complete block design with two replications in 1995 and three in 1996. In 1995, because of limited seed, each plot consisted of a single $2.44-\mathrm{m}$ row with $0.36 \mathrm{~m}$ between rows (again planted at the normal seeding rate). In 1996, each plot consisted of four rows $2.44 \mathrm{~m}$ with $0.36 \mathrm{~m}$ between rows. At Aberdeen, the two center rows were harvested. At Tetonia, all four rows were harvested. Every eighteenth plot was planted to Crystal II barley to differentiate plots.

For ditelosomic lines, days to heading (HD), grain yield (GY), and $100-\mathrm{KW}$ were measured at each trial. For the euploid lines, HD (measured at Aberdeen, 1995 and 1996 only), GY, grain volume weight (GVW), and 100-KW were measured at each trial. Days to heading were visually estimated from the date of planting to the date when $50 \%$ of the spikes emerged from the flag leaf in a plot. After harvest, all seeds were cleaned and weighed to determine GY, GVW, and 100-KW.

\section{End-Use Quality Analysis}

To determine the end-use quality, a 35-g grain sample of each line was tempered to a $152 \mathrm{~g} \mathrm{H}_{2} \mathrm{O} 1000 \mathrm{~g}^{-1}$ grain moisture basis for $18 \mathrm{~h}$ and milled on a Brabender Quadraplex laboratory mill (C.W. Brabender Instruments, Inc., South Hackensack, NJ). The FP content was determined from a 1-g sample on a $140 \mathrm{mg} \mathrm{H}_{2} \mathrm{O} \mathrm{g}^{-1}$ flour basis by the Udy Dye binding method (AACC, 1995, Method 46-14A), and periodically verified with $140 \mathrm{mg} \mathrm{H}_{2} \mathrm{O} \mathrm{g}^{-1}$ flour moisture basis with a LECO $\mathrm{N}$ analysis (AACC, 1995, Method 46-30) by the Soil Analytical Laboratory, Department of Agronomy, University of Nebraska, Lincoln. Mixograph characteristics were evaluated with the AACC (1995) Method 54-40A, with a 10-g sample (140 $\mathrm{g} \mathrm{H}_{2} \mathrm{O} 1000 \mathrm{~g}^{-1}$ flour moisture basis) and constant water absorption of $620 \mathrm{~g} \mathrm{H}_{2} \mathrm{O} 1000 \mathrm{~g}^{-1}$ flour with a National manufacturing Mixograph (AACC, 1995). The MT was recorded as the time in minutes to optimal dough development, and MTO was measured with a scale from 0 to 7 , with higher scores indicating greater tolerance. The SDSS test was performed with $2 \mathrm{~g}$ (140 $\mathrm{g} \mathrm{H}_{2} \mathrm{O} 1000 \mathrm{~g}^{-1}$ flour) of flour with a modified AACC (1995) method 56-61A, and the sedimentation volume was recorded after $20 \mathrm{~min}$ in milliliters.

\section{Statistical Analysis}

Analysis of variance was performed on the ditelosomic lines and Pavon 76 across two environments, and the euploid lines across three environments. Environments and replications were considered as random effects, and lines were considered fixed. The respective error term for the $F$ test was estimated with the random statement with test option in the PROCGLM from SAS procedure (SAS Institute, 1988a). The significance and variances between lines and controls were determined with the $F$ test. Lines and controls were compared with $t$ test or single degree of freedom contrasts for all traits (SAS Institute, 1988b). For 2- and 3-df contrasts, the least square means and the standard errors were determined with the PROC-MIXED procedure (SAS Institute, 1992, p. 229).

\section{RESULTS}

Significant differences $(P<0.05)$ among ditelosomic lines were observed for 100-KW, FP, MT, MTO, and the SDSS, but not for the HD and GY (Table 1). No significant differences for HD suggest that the group 1 chromosome arms do not affect this characteristic. The differences for GY were large but not statistically significant because of absence of replications in each year of

Table 1. Means of ditelosomic lines grown in Aberdeen, ID, in 1995 and 1996 for agronomic and end-use quality traits.

\begin{tabular}{|c|c|c|c|c|c|c|c|}
\hline & Heading date & Grain yield & 100-kernel weight & Flour protein & Mixing time & Mixing tolerance & SDSS $\dagger$ \\
\hline & DOY $\%$ & $\mathbf{k g ~ h a}^{-1}$ & $\mathbf{g}$ & $\mathbf{m g ~ g ^ { - 1 }}$ & $\min$ & score & $\mathbf{m L}$ \\
\hline Dt $1 \mathrm{AS}$ & 193.5 & 1476 & 3.50 & 157 & 1.90 & 1.65 & 25.8 \\
\hline Dt $1 \mathrm{AL}$ & 197.0 & 3896 & 3.75 & 128 & 2.85 & 2.85 & 37.0 \\
\hline Dt 1BL & 195.5 & 2957 & 3.80 & 137 & 2.95 & 2.80 & 38.0 \\
\hline Dt $1 D S$ & 196.5 & 2063 & 3.85 & 150 & 1.15 & 0.00 & 5.0 \\
\hline Dt 1DL & 194.0 & 1642 & 3.00 & 165 & 1.90 & 1.80 & 36.5 \\
\hline 'Pavon 76' & 195.5 & 4437 & 3.90 & 127 & 3.10 & 2.50 & 38.3 \\
\hline Mean & 195.3 & 2737 & 3.63 & 144 & 2.31 & 1.95 & 30.1 \\
\hline LSD0.05 & NS & NS & 0.43 & 18 & 0.60 & 1.11 & 7.6 \\
\hline
\end{tabular}

$\uparrow$ SDSS, sodium dodecyl sulfate sedimentation.

$\uparrow$ DOY, day of year. 
tests. Replications were precluded by limited seed that had to be produced in absence of cross pollination. However, the pattern of GY differences was the same as that observed during several cycles of greenhouse seed increases. Short-arm ditelosomics always produce less grain than the long-arm ditelosomics; among the short arms, Dt1BS always has the lowest seed set. Among the five lines tested in the field, only Dt 1DL had significantly lower $100-\mathrm{KW}$ than Pavon 76 . This may be a result of a much more speltoid-like head shape with smaller and tougher glumes relative to the other two long-arm ditelosomics and, especially, to Pavon 76. Ditelosomic 1AS, 1DS, and 1DL had significantly higher FP and lower MT than Pavon 76. Only Dt 1DS had a significantly lower MTO than Pavon 76, and both Dt 1AS and Dt 1DS had significantly lower SDS-sedimentation than Pavon 76. Dt 1AL and Dt 1BL lines were not significantly different from Pavon 76 for FP, MT, and MTO.

Among the euploid lines, in all groupings, the means of the representative controls were not different from Pavon 76. This indicates that the procedures used in the development of the substitution and translocation lines were appropriate in that the number of backcrosses and selection for Pavon 76-like morphology were sufficient to eliminate the residual background variation. Consequently, where specific control sib-lines were not made, the comparisons to Pavon 76 are likely to be appropriate.

Significant differences were observed for all agronomic and end-use quality traits among the euploid lines. The environment $\times$ genotype interaction was also significant for HD, GY, GVW, 100-KW, MTO, and SDSS. No significant environment $\times$ genotype interaction was present for FP and MT. The environment $\times$ genotype interaction was mainly because of changes in magnitude rather than changes in order, hence the genotype means can be discussed here. While numerous comparisons can be made from the genotype means (Table 2), only those comparisons that are most important in understanding the role of rye chromosome 1 and its arms in wheat will be discussed.

Among substitutions involving complete chromosome 1R, no significant variation was found for $\mathrm{HD}$, GY, FP, MT, and SDS-sedimentation between $1 \mathrm{R}_{\mathrm{e}}(1 \mathrm{~A})$ and its control; however, $1 \mathrm{R}_{\mathrm{e}}(1 \mathrm{~A})$ control line had significantly heavier GVW and 100-KW, and higher MTO. No significant differences were found for HD, GY, 100$\mathrm{KW}$, FP content, and MT between $1 \mathrm{R}_{\mathrm{e}}(1 \mathrm{~B})$ and its control, which had significantly higher GVW, MTO, and SDSS. The $1 R_{e}(1 D)$ line had significantly lower GY, GVW, 100-KW, MT, MTO, and SDSS, but higher FP than its control. As the same $1 \mathrm{R}_{\mathrm{e}}$ was used in all three substitutions, replacing $1 \mathrm{~B}$, and even more so, $1 \mathrm{D}$, with $1 R_{e}$ is undesirable based on agronomic and end-use quality traits. The substitution lines involving the reconstructed chromosome $1 \mathrm{R}\left(1 \mathrm{RS}_{\mathrm{v}} \cdot 1 \mathrm{RL}_{\mathrm{e}}\right)$ generally showed a similar pattern to the $1 \mathrm{R}_{\mathrm{e}}$ substitution lines. As the two chromosomes differ only by the short arms, $1 \mathrm{RS}_{\mathrm{v}}$ must be similar to $1 \mathrm{RS}_{\mathrm{e}}$ in its effects on the agronomic performance and quality parameters.
Among the centric translocations introgressed into Pavon 76 from various sources, the $1 \mathrm{RS} .1 \mathrm{AL}_{\mathrm{am}}$ line had significantly lower MTO and SDSS than its control. $1 \mathrm{RS} .1 \mathrm{BL}_{\mathrm{cim}}$ translocation had significantly lower MT, MTO, and SDSS than its control. $1 \mathrm{RS} .1 \mathrm{BL}_{\mathrm{cim}}$ and $1 \mathrm{RS} .1 \mathrm{BL}_{\mathrm{gnr}}$ were not different for GY, GVW, 100-KW, $\mathrm{FP}$, and SDSS. However, $1 \mathrm{RS} .1 \mathrm{BL}_{\mathrm{gnr}}$ had significantly earlier HD, and significantly higher MT and MTO than the $1 \mathrm{RS} .1 \mathrm{BL}_{\mathrm{cim}}$ line. Translocation $1 \mathrm{RS} .1 \mathrm{DL}_{\mathrm{bb}}$ line had significantly later HD and lower GY, MT, MTO, and SDSS than its control. Later heading and a substantial reduction in yield may be a result of the very short stature of this line that is not related to the presence of the rye introgression. Such dwarfs segregate out in various hybrids of Pavon 76 with a low but regular frequency. $1 \mathrm{RS} .1 \mathrm{DL}_{\mathrm{w}}$ and $1 \mathrm{RS} .1 \mathrm{DL}_{\mathrm{bb}}$ were similar for most traits (except GY and FP). 1DS.1RL $\mathrm{L}_{\mathrm{bb}}$ had significantly higher FP, but lower GY, GVW, 100-KW, MT, and MTO than its control.

To better understand the role of 1RS, a series of centric wheat-rye translocations were created that involved the same $1 \mathrm{RS}$ arms $\left(1 \mathrm{RS}_{\mathrm{e}}\right.$ or $\left.1 \mathrm{RS}_{\mathrm{v}}\right)$ but in different positions in the wheat genome. Among the translocation of $1 \mathrm{RS}_{\mathrm{e}}$, that to $1 \mathrm{AL}$ had higher GY, and that to 1DL had lower GY but higher 100-KWT, than their respective controls. $1 \mathrm{RS}_{\mathrm{e}} .1 \mathrm{BL}$ was not different from Pavon 76. Among the translocations of $1 \mathrm{RS}_{\mathrm{v}}$, that to $1 \mathrm{AL}$ had a later HD and lower GY, that to $1 \mathrm{BL}$ was not different, and that to $1 \mathrm{DL}$ had a later HD, lower GVW, but higher 100-KWT than their controls. For end-use quality, both sets of three translocation lines involving 1RS had significantly lower MT or MTO and SDSS values than their controls or Pavon 76.

Among the translocations involving the long arm of $1 \mathrm{R}_{\mathrm{e}}, 1 \mathrm{AS}_{\mathrm{p}} \cdot 1 \mathrm{RL}_{\mathrm{e}}$ had lower GY and GVW, heavier 100KW, and higher FP, MT, MTO, and SDSS values than its control, indicating that as far as the end-use quality was concerned, $1 \mathrm{RL}_{\mathrm{e}}$ was superior to $1 \mathrm{AL}_{\mathrm{p}}$. The $1 \mathrm{BS}_{\mathrm{p}} .1 \mathrm{RL} \mathrm{L}_{\mathrm{e}}$ line had significantly earlier $\mathrm{HD}$, and higher FP content and SDSS, but significantly lower GY, GVW, and $100-\mathrm{KW}$ than its control. $1 \mathrm{DS}_{\mathrm{p}} \cdot 1 \mathrm{RL}_{\mathrm{e}}$ translocation had significantly earlier HD, higher FP content, but lower GY, GVW, 100-KW, MT, and MTO, indicating the absence of the 1DL arm contributed to the deleterious end-use quality of wheat flour.

Among the lines with translocations involving portions of chromosome arms $1 \mathrm{RS}$ and 1BS, the informative comparisons are for $1 \mathrm{~B}_{\text {ins }}$ vs. $1 \mathrm{RS}$ ins. $1 \mathrm{BL}$ and $1 \mathrm{R}_{\text {ins }} \mathrm{vs}$. $1 \mathrm{BS}_{\text {ins. }}$. $\mathrm{RL}$. The first pair includes chromosomes $1 \mathrm{~B}$ that differ by the presence of a proximal $\left(1 \mathrm{BS}_{\mathrm{ins}}\right)$ or terminal $\left(1 \mathrm{RS} \mathrm{ins}_{1} .1 \mathrm{BL}\right)$ segment involving $1 \mathrm{RS}$. Presence of the terminal segment involving 1RS eliminates the Gli-B1 and $G l u-B 3$ loci of wheat and introduces rye $S e c-1$ locus. $1 \mathrm{~B}_{\text {ins }}$ and $1 \mathrm{RS}_{\text {ins. }} .1 \mathrm{BL}$ were similar for GY, FP, MT, MTO, and SDSS. $1 \mathrm{RS}_{\text {ins. }} 1 \mathrm{BL}$ was earlier heading and had higher GVW and $100-\mathrm{KW}$ than $1 \mathrm{~B}_{\text {ins }}$. The second pair of translocations includes chromosomes $1 \mathrm{R}$ that differ by the presence of a proximal or terminal segment involving 1BS (see Lukaszewski, 1993, 1997), substituted for 1B. Presence of the terminal rye segment introduces the rye Sec-1 locus and eliminates Gli-B1 and Glu-B3 
Table 2. Means of euploid lines (chromosome substitutions and translocations) grown in Aberdeen, ID, in 1995 and 1996, and in Tetonia, ID, in 1996 for agronomic and end-use quality traits.

\begin{tabular}{|c|c|c|c|c|c|c|c|c|}
\hline & $\begin{array}{l}\text { Heading } \\
\text { date }\end{array}$ & $\begin{array}{l}\text { Grain } \\
\text { yield }\end{array}$ & $\begin{array}{c}\text { Grain } \\
\text { volume weight }\end{array}$ & $\begin{array}{c}\text { 100-kernel } \\
\text { weight }\end{array}$ & $\begin{array}{c}\text { Flour } \\
\text { protein }\end{array}$ & $\underset{\text { time }}{\text { Mixing }}$ & $\begin{array}{l}\text { Mixing } \\
\text { tolerance }\end{array}$ & SDSS $\dagger$ \\
\hline & DOY $\div$ & $\mathbf{k g ~ h a}^{-1}$ & $\mathbf{k g ~ h} \mathbf{L}^{-1}$ & $\mathbf{g}$ & $\mathbf{m g ~ g ^ { - 1 }}$ & $\min$ & score & $\mathbf{m L}$ \\
\hline \multicolumn{9}{|l|}{ Lines } \\
\hline $\mathbf{1} \mathbf{R}_{\mathrm{e}}(\mathbf{1 A}) \S$ & 198.3 & 3243 & 78.6 & 3.14 & 145 & 3.25 & 2.60 & 38.0 \\
\hline $1 R_{\mathrm{e}}(1 \mathrm{~A})$ control & 198.3 & 3548 & 80.5 & 3.54 & 139 & 3.05 & 3.08 & 37.4 \\
\hline $1 R_{\mathrm{e}}(\mathbf{1 B})$ & 199.0 & 3491 & 78.9 & 3.32 & 146 & 2.58 & 0.40 & 31.3 \\
\hline $1 R_{\mathrm{e}}(1 \mathrm{~B})$ control & 198.3 & 3489 & 80.2 & 3.51 & 143 & 2.75 & 2.75 & 37.2 \\
\hline $1 R_{\mathrm{e}}(1 \mathrm{D})$ & 197.1 & 3188 & 78.1 & 3.17 & 149 & 1.58 & 0.00 & 22.4 \\
\hline $1 R_{\mathrm{e}}(1 \mathrm{D})$ control & 198.0 & 3909 & 81.5 & 3.87 & 137 & 2.70 & 2.50 & 37.1 \\
\hline $\mathbf{1 R}_{\mathbf{R E C}}(\mathbf{1 A})\left(=\mathbf{R S}_{\mathbf{v}} \cdot \mathbf{1 R L _ { \mathrm { e } } )}\right.$ & 198.7 & 3412 & 77.6 & 3.14 & 148 & 3.47 & 2.50 & 39.2 \\
\hline $1 R_{\text {REC }}(1 B)\left(=R \cdot 1 R L_{e}\right)$ & 198.8 & 3250 & 78.5 & 3.47 & 147 & 2.53 & 0.58 & 31.8 \\
\hline $\mathbf{1 R}_{\mathrm{REC}}\left(\mathbf{1 D )}\left(=\mathbf{R S}_{\mathbf{v}} .1 \mathbf{R} \mathbf{L}_{\mathrm{e}}\right)\right.$ & 201.5 & 3048 & 76.4 & 3.06 & 151 & 1.48 & 0.00 & 22.9 \\
\hline $1 R_{\text {REC }}(1 B)$ ( = 1BSp.1BLv) & 196.8 & 3903 & 81.4 & 3.67 & 132 & 2.79 & 3.08 & 36.9 \\
\hline \multicolumn{9}{|l|}{ Translocation substitutions } \\
\hline 1RS.1AL $L_{\text {am }}$ & 199.4 & 3497 & 79.3 & 3.67 & 139 & 2.53 & 1.93 & 29.1 \\
\hline 1RS.1AL $\mathrm{Lam}_{\mathrm{am}}$ control & 198.1 & 3776 & 80.5 & 3.64 & 138 & 2.80 & 3.18 & 36.3 \\
\hline 1RS.1BL $\mathrm{c}_{\mathrm{cm}}$ & 199.1 & 3839 & 79.6 & 3.77 & 136 & 2.05 & 0.50 & 23.8 \\
\hline 1RS.1BL ${ }_{\mathrm{clm}}$ control & 198.8 & 4034 & 79.4 & 3.82 & 136 & 3.00 & 3.08 & 38.3 \\
\hline 1RS.1BL & 196.6 & 3556 & 80.0 & 3.95 & 140 & 2.61 & 1.48 & 26.3 \\
\hline 1DS.1RL $\mathbf{L}_{\mathrm{bb}}$ & 198.2 & 2889 & 78.3 & 3.05 & 156 & 1.97 & 0.90 & 35.4 \\
\hline 1DS.1RL $_{b b}$ control & 197.8 & 3653 & 80.0 & 3.74 & 137 & 3.08 & 3.15 & 37.7 \\
\hline 1RS.1DL $L_{b b}$ & 199.5 & 2214 & 80.2 & 3.61 & 145 & 2.10 & 1.00 & 27.1 \\
\hline 1RS.1DL $_{b b}$ control & 197.7 & 4046 & 81.2 & 3.83 & 137 & 2.93 & 3.30 & 38.8 \\
\hline 1RS.1DL $L_{w}$ & 200.7 & 3666 & 80.6 & 3.79 & 135 & 2.22 & 0.90 & 26.8 \\
\hline 1RS.1DL ${ }_{w}^{w}$ control & 197.6 & 3855 & 80.7 & 3.80 & 136 & 2.87 & 3.48 & 36.7 \\
\hline \multicolumn{9}{|l|}{ Arm substitutions } \\
\hline $1 A S_{\mathrm{p}} 1 R L_{\mathrm{e}}$ & 196.7 & 2966 & 77.8 & 2.76 & 146 & 4.23 & 4.23 & 40.7 \\
\hline $\mathbf{A S}_{\mathrm{p}} 1 \mathbf{R L} \mathrm{L}_{\mathrm{e}}$ control & 197.3 & 3655 & 79.7 & 2.55 & 134 & 3.15 & 3.08 & 37.3 \\
\hline 1RSe 1AL $_{p}$ & 198.4 & 4015 & 81.1 & 4.00 & 133 & 2.45 & 3.18 & 29.6 \\
\hline 1RSe 1 AL $L_{p}$ control & 197.3 & 3537 & 81.3 & 3.95 & 138 & 2.80 & 2.98 & 37.3 \\
\hline $1 B S_{\mathrm{p}} 1_{\mathrm{RL}}$ & 195.8 & 2852 & 78.7 & 3.21 & 153 & 2.65 & 2.43 & 40.3 \\
\hline 1BS $_{\mathrm{p} .1 R L_{\mathrm{e}}}$ control & 197.9 & 3747 & 80.3 & 3.79 & 136 & 2.82 & 2.90 & 36.8 \\
\hline $1 \mathrm{RS}_{\mathrm{e} .} 1 \mathrm{BL} \mathrm{L}_{\mathrm{p}}$ & 198.0 & 4151 & 81.0 & 3.86 & 130 & 2.73 & 1.58 & 26.3 \\
\hline $\mathbf{1 R S}_{\mathrm{e} .1 \mathrm{BL}}$ control & 197.6 & 3875 & 80.6 & 3.68 & 135 & 3.02 & 3.10 & 37.0 \\
\hline $\operatorname{1DS}_{\mathrm{p}} 1 \mathrm{RL} \mathrm{L}_{\mathrm{e}}$ & 197.5 & 3005 & 78.4 & 3.04 & 148 & 1.85 & 0.55 & 34.5 \\
\hline $\operatorname{1DS}_{\mathrm{p}} 1 \mathrm{RL} \mathrm{L}_{\mathrm{e}}$ control & 199.0 & 3714 & 80.8 & 3.67 & 135 & 2.80 & 3.00 & 37.0 \\
\hline $\operatorname{1RS}_{\mathrm{e}} 1 \mathrm{DL}$ & 198.3 & 3314 & 81.0 & 4.04 & 138 & 2.17 & 1.15 & 28.8 \\
\hline $1 \mathrm{RS}_{\mathrm{e}} 1 \mathrm{DL} \mathrm{L}_{\mathrm{p}}$ control & 197.3 & 3836 & 80.8 & 3.83 & 138 & 2.75 & 2.93 & 36.1 \\
\hline $\mathbf{1 R S}_{\mathrm{v}} \mathbf{1 A L}_{\mathrm{p}}$ & 199.3 & 3839 & 81.1 & 3.79 & 140 & 2.48 & 2.25 & 31.0 \\
\hline $\mathbf{1 R S}_{\mathrm{v}} 1 \mathrm{AL} \mathrm{L}_{\mathrm{p}}$ control & 198.1 & 4297 & 80.1 & 3.67 & 135 & 3.07 & 3.25 & 37.7 \\
\hline 1RS $_{\mathrm{v}} 1 \mathrm{BL}_{\mathrm{p}}$ & 197.9 & 3876 & 81.1 & 3.86 & 139 & 2.67 & 2.08 & 27.8 \\
\hline $1 \mathrm{RS}_{\mathrm{v}} 1 \mathrm{BL}_{\mathrm{p}}$ control & 197.5 & 3744 & 81.5 & 3.82 & 133 & 2.78 & 3.18 & 35.3 \\
\hline $\mathbf{1 R S}_{\mathrm{v}} \mathbf{1 D L} \mathrm{L}_{\mathrm{p}}$ & 200.7 & 3644 & 79.2 & 3.96 & 144 & 2.27 & 0.83 & 28.9 \\
\hline $\mathbf{1 R S}_{\mathrm{e} .} \mathbf{1 B L _ { \mathrm { v } }}$ & 197.8 & 4136 & 81.0 & 3.80 & 127 & 2.65 & 1.23 & 25.0 \\
\hline \multicolumn{9}{|l|}{ Chromosome rearrangements } \\
\hline $1 B_{\text {ins }}(1 B)$ & 201.4 & 3727 & 77.6 & 3.60 & 134 & 2.18 & 0.85 & 22.7 \\
\hline $1 R_{\text {ins }}(1 B)$ & 197.6 & 2935 & 78.8 & 3.31 & 157 & 2.18 & 0.15 & 30.1 \\
\hline 1R.1D $_{5+10^{-2}}$ (1A) & 197.8 & 3137 & 77.8 & 3.07 & 143 & 4.07 & 3.75 & 38.3 \\
\hline 1R.1D $_{5+10^{-2}}$ (1D) & 200.0 & 3034 & 78.0 & 3.20 & 149 & 2.07 & 0.43 & 31.6 \\
\hline $\mathbf{1 R S}_{\text {ins. }} 1 \mathrm{BL}(\mathbf{1 B}+)$ & 198.1 & 3444 & 81.0 & 4.03 & 140 & 2.42 & 1.00 & 24.8 \\
\hline $\mathbf{1 B S}_{\text {ins. }} 1 \mathrm{RL}(1 \mathrm{R}+)$ & 199.8 & 3173 & 75.0 & 3.27 & 145 & 2.05 & 0.00 & 28.5 \\
\hline \multicolumn{9}{|l|}{ Overall control cultivar } \\
\hline 'Pavon 76' & 197.9 & 3806 & 81.0 & 3.79 & 132 & 2.93 & 3.00 & 37.0 \\
\hline Mean & 198.3 & 3543 & 79.7 & 3.57 & 140 & 2.64 & 2.03 & 32.8 \\
\hline LSD0.05 & 1.1 & 438 & 1.2 & 0.20 & 8 & 0.30 & 0.47 & 2.5 \\
\hline
\end{tabular}

† SDSS, sodium dodecyl sulfate sedimentation.

+ DOY, day of year.

$\S$ The subscript abbreviations are for the source of rye or wheat chromatin $(p=$ 'Pavon 76 '; $\mathbf{v}=$ 'Veery', gnr $=$ Genaro $($ Veery $)$; am $=$ Amigo; bb $=$ BH1146/'Blanco'; e = E12165 (CIMMYT); cim = E12169 (CIMMYT); and w = 'Wheaton'.

of wheat; while the presence of the proximal rye segment does not affect the composition of the storage protein loci of wheat. $1 \mathrm{R}_{\text {ins }}$ and $1 \mathrm{BS}_{\text {ins }} .1 \mathrm{RL}$ were similar for GY, 100-KW, MT, MTO, and SDSS. 1 $\mathrm{R}_{\text {ins }}$ was earlier and had higher GVW and FP than $1 \mathrm{BS}_{\text {ins. }}$ 1RL. Apart from the pair-wise comparisons, the first pair of chromosomes $\left(1 \mathrm{~B}_{\text {ins }}\right.$ and $\left.1 \mathrm{RS}_{\mathrm{ins}} .1 \mathrm{BL}\right)$ is directly comparable with Pavon 76 and the $1 \mathrm{RS} .1 \mathrm{BL}$ translocated lines, respectively; the second pair $\left(1 \mathrm{R}_{\text {ins }}\right.$ and $\left.1 \mathrm{BS}_{\mathrm{ins}} .1 \mathrm{RL}\right)$ is comparable with the substitutions involving $1 \mathrm{R}$ and translocations involving 1RL. On another level, the lines with Sec-1 present and Gli-B1/Glu-B3 absent $\left(1 \mathrm{RS}_{\text {ins. }}\right.$. BL and $1 \mathrm{R}_{\mathrm{ins}}$ ) are equivalent in their genetic composition at the storage protein loci to the $1 \mathrm{RS} .1 \mathrm{BL}$ wheats; those with Sec-1 absent and Gli-B1/Glu-B3 present $\left(1 \mathrm{~B}_{\text {ins }}\right.$ and $1 \mathrm{BS}_{\text {ins. }}$ 1RL) are equivalent to Pavon 76.

Similar to the substitutions involving complete chromosomes $1 \mathrm{R}$ and centric translocations, in the lines with small inserts on the short arms, 1RL significantly reduced GY and 100-KW, and increased FP. No clear effects of the two portions involving $1 \mathrm{RS}$, proximal in $1 \mathrm{RS}_{\text {ins }} .1 \mathrm{BL}$, and terminal in $1 \mathrm{~B}_{\text {ins }}$ on any of these characteristics were evident. Among quality parameters, three lines were similar to the corresponding centric translocations or substitutions involving $1 \mathrm{R}$ with the same composition at the storage protein loci, with one exception. 
The exception was $1 \mathrm{BS}_{\text {ins. }}$ 1RL that had lower MT, MTO, and SSDS values relative to the $1 B S .1 R L_{e}$ line despite the same storage protein loci present. The reasons for this reduction are not clear.

Introgression involving the engineered chromosome $1 \mathrm{R} .1 \mathrm{D}_{5+10}-2$ into Pavon 76 in substitutions either for $1 \mathrm{D}$ or $1 \mathrm{~A}$ had a similar detrimental effect on the agronomic performance as any substitution of a normal chromosome 1R: reduction in GY, GVW, and 100-KW with an associated increase in FP. Among the quality effects, substitution $1 \mathrm{R} .1 \mathrm{D}_{5+10}-2$ for $1 \mathrm{D}$ reduced all parameters tested to the same level as any 1RS.1DL translocation. Because Glu-D1 is present on the engineered 1RL and Sec-3 is absent, the locus composition of the $1 \mathrm{R} .1 \mathrm{D}_{5+10^{-}}-2$ (1D) line is identical to that of 1RS.1DL. Substitution of $1 \mathrm{R} .1 \mathrm{D}_{5}+10^{-2}$ for $1 \mathrm{~A}$ significantly increased MT and MTO over Pavon 76 but did not affect SDSS. Two additional doses of the Glu-D1 locus replacing Glu-A1 were capable of compensating for the absence of $1 \mathrm{AS}$ and the presence of $1 \mathrm{RS}$ with Sec-1.

\section{DISCUSSION}

Most aneuploid stocks of wheat have reduced seed set and other associated agronomic problems that make them unsuitable for field trials. Their reduced fertility makes them prone to outcrossing, hence production of the required seed quantities of acceptable purity is a problem. Consequently, there have been few experiments that included such lines. But whenever conducted, such experiments offer new insights on the effects of individual chromosomes and chromosome arms on various characteristics of wheat. In this experiment, primarily designed to determine the effects of the introgressions of rye chromosome $1 \mathrm{R}$ on wheat, we attempted to establish the relative contributions of the individual arms of group 1 chromosomes of wheat on agronomic and end-use quality characteristics. Because of the limitations of the ditelosomic lines, they had to be grown in a separate experiment that could be repeated but not replicated, which precludes many direct comparisons with the euploid lines. Still, it is clear that group 1 chromosomes do not affect such parameters as days to heading. While the differences for GY among the five ditelosomics tested were large, they were not statistically significant. However, keeping in mind that the seed set of Dt 1BS was so low that the minimum amount of seed required could not be produced in time, it would appear that the absence of the long arms of the group 1 chromosomes had a far more negative impact on yield than the absence of the short arms (average GY of 1769 vs. $2832 \mathrm{~kg} \mathrm{ha}^{-1}$ for Dt S and Dt L, respectively). Among the long-arm ditelosomics (short arms missing), Dt1AL had a GY that was close to Pavon 76, the GY of Dt 1DL was only $37 \%$ of Pavon 76 . These observations show that there are large differences among the individual arms within the homeologous group 1 in their effects on yield. The short arms of group 1 chromosomes of Pavon 76 contribute much less to yield than the long arms, and among short arms, the contribution of $1 \mathrm{AS}$ is the smallest while that of 1DS is the largest. These observations from limited replications in the field are fully supported by observations on many greenhousegrown generations. Therefore, if an assumption is made that the contribution of $1 \mathrm{RS}$ to yield is the same regardless of its position in the wheat genome, translocation 1RS.1AL would have the highest yield and 1RS.1DL the lowest.

Similarly, cautious conclusions can be drawn on the effects of individual arms of group 1 chromosomes on the tested parameters of quality. Small reductions of the parameters among the ditelosomics for the long arms indicate that the impact of the short arms was low. Of the two long arms tested, 1AL and 1DL, the effect of 1DL was much larger; data discussed later will show that the effect of 1BL must also be quite large. In a detailed study of the contribution of the individual group 1 and 6 chromosomes and their arms to breadmaking quality in the 'Chinese Spring' wheat, Rogers et al. (1990) identified 1D as the most important chromosome in group 1; $1 \mathrm{~A}$ was ranked as contributing the least and the long arms were generally more important than the short arms. The differences and relative contributions of individual chromosomes and chromosome arms in the study of Rogers et al. (1990) and those observed here may be attributed to a considerable difference in the overall quality of Chinese Spring and Pavon 76, and to the effects of different alleles present at different loci. Interestingly, the contribution of $1 \mathrm{AL}$ to end-use quality was low in both wheats even though Chinese Spring carries allele $c$ (null) at $G l u-1 A$ while Pavon 76 carries allele $a$ (Subunit 1). So, while some care needs to be exercised in interpreting the results of this experiment because of its limited scale, the observed trends are in complete agreement with the study of Rogers et al. (1990).

All substitutions of complete $1 \mathrm{R}$, regardless of its position in the wheat genome (for 1A, 1B or 1D), including the substitutions of the engineered $1 \mathrm{R} .1 \mathrm{D}_{5}+10^{-} 2$, significantly reduced GY, GVW, and $100-\mathrm{KW}$ relative to Pavon 76 and to the means of the 16 lines used here as controls (Table 2). A comparison of the means for the translocation lines of $1 \mathrm{RS}$ to the long arms of wheat group 1 chromosomes with the means for the translocation lines of 1RL to the short arms of wheat arms clearly indicate that $1 \mathrm{RL}$ was entirely responsible for these reductions. On average, $1 \mathrm{RS}$ had little negative impact on the agronomic performance of the lines and, at least in some whole chromosome substitution lines, it appeared to compensate to some extent for the negative effect of 1RL. On the basis of GY means, the three translocations of $1 \mathrm{RS}$ can be ranked in the order of descending agronomic performance as $1 \mathrm{RS} .1 \mathrm{BL}>$ 1RS.1AL $>1$ RS.1DL. This suggests that the position of $1 \mathrm{RS}$ in the wheat genome is important. It needs to be reiterated that among the tested translocation lines there were two sets of three translocations involving the identical $1 R S$ arm $\left(1 R_{e}\right.$ and $\left.1 R_{v}\right)$; the same $1 R \cdot 1 D_{5}+10^{-2}$ was also substituted into two different positions. Therefore, disregarding some effects of background variation, still possible after up to 10 backcrosses, any differences among the translocation lines can be attributed 
to one of two factors: the position effect of the 1RS arm and the effect of the missing (substituted) wheat chromosome arm, or a combination of both. Among the long-arm ditelosomics, the ranking based on GY was $1 \mathrm{AL}>1 \mathrm{BL}>1 \mathrm{DL}$ and was identical to that based on seed set under greenhouse conditions (Lukaszewski, 1996, unpublished data). It therefore appears likely that the enhanced agronomic performance of the 1RS.1BL translocation is because of the position effect of 1RS. Significant differences among the three translocation lines that do not mirror the differences among the $1 \mathrm{~L}$ ditelosomic lines make it implausible that increased yield of the translocation lines would be because of the presence of an undefined quantitative trait locus on 1RS, as postulated by Schlegel and Meinel (1994). If present, such a locus should be expressed regardless of the position of 1RS in the wheat genome. Instead, the position effect of 1RS may be a result of fixed heterosis between rye and wheat chromatin, with its magnitude dependent on the combination of the arms present. If this speculation is correct, the best heterosis among the $1 \mathrm{~S}$ arms in wheat is in the $1 \mathrm{AS}, 1 \mathrm{RS}, 1 \mathrm{DS}$ combination. Combination 1AS, 1BS, 1RS appears to have negative heterosis. Yield enhancements have been associated with the presence of other rye introgressions in wheat (Fritz and Sears, 1991), and even with the introgression of an Agropyron elongatum segment (Singh et al., 1998). Intergeneric heterosis of the entire rye genome with Genomes A and B of wheat may well be responsible for the extraordinary vigor and high yield potential of triticale, except that unlike the entire genomes in triticale (combination A B R), 1RS in wheat produces a better effect in the 1AS, 1RS, 1DS combination.

Among the ditelosomics, Dt 1AS and Dt 1DL had significantly higher FP content than Pavon 76. This was probably a result of severe GY reduction in these lines. Higher protein content did not necessarily translate into higher parameters indicative of breadmaking quality. Taking all parameters together, it appeared that absence of the short arms had little effect on quality; the effect of the long arms was large. Substitutions of complete $1 \mathrm{R}$ (here, excluding the engineered $1 \mathrm{R} .1 \mathrm{D}_{5+10}-2$ ) as well as all translocations of 1RL to the short arms of wheat group 1 chromosomes had significantly higher total protein content than Pavon 76, the controls, and the 1RS translocation lines. On the other hand, the means for all the 1RS translocation lines combined did not differ from the controls and Pavon 76. Similar to the ditelosomics, the increase in protein content of the 1RL-containing lines appears related to their significant yield reduction. Similar arm-based generalizations can be made for the mixing time, mixing tolerance, and the SDSS value. While the average mixing time for all substitutions of $1 \mathrm{R}$ and all translocations of $1 \mathrm{RL}$ did not differ significantly from the mean of all controls and Pavon 76, clear differences among the sets of substitutions and translocation indicate that the quality effects were at least partially dependent on the position of the rye arm in the wheat genome (Table 2). Among the translocations of $1 \mathrm{RL}$, those to $1 \mathrm{AS}$ had significantly higher MT and the same MTO and SDSS value as the controls and Pavon 76, while for those to 1DS all these parameters were significantly lower. Given that the same 1RL arms were used in all three positions, the data permit ranking of the contribution of the $1 \mathrm{~L}$ arms to quality, from the highest to lowest, $1 \mathrm{DL}>1 \mathrm{BL}>$ $1 \mathrm{RL}>1 \mathrm{AL}$. Rye chromosome arm $1 \mathrm{RL}_{\mathrm{e}}$ offered better contribution to quality than Pavon 76's 1AL.

All three translocation lines involving $1 \mathrm{RS}_{\mathrm{e}}$ and all three translocations involving $1 \mathrm{RS}_{\mathrm{v}}$ had significantly lower quality parameters than their controls. Because identical 1RS chromosome arms were present in all three translocations in each set, and there was no significant background variation in this experiment, the differences among the lines in each set can be attributed to the absence of wheat storage protein loci eliminated by the introduction of $1 \mathrm{RS}$, or to the interactions of the remaining loci. The experiment with ditelocentric lines of Pavon 76 has shown that the removal of the short arms of wheat group 1 chromosomes had minimal effects on the same parameters (Table 1). Hence, the introduction of the Sec-1 encoded secalins into wheat, and not the removal of the corresponding wheat storage protein loci, is primarily responsible for the reduction of the end-use quality in the translocated lines. The position of $1 \mathrm{RS}$ in the wheat genome is also important, with 1RS.1AL translocation demonstrating the least reduction in each of the three end-use quality parameters tested, and 1RS.1DL the most. Among the long-arm ditelosomics, only 1DL showed a significant reduction of MT relative to Pavon 76, though MTO and the SDSS values were not affected by the absence of the short arms. This suggests that some interactions between the $1 \mathrm{RS}$-encoded secalins and wheat storage proteins may also be responsible for the quality defect of the translocation lines. The observations permit ranking of the three $1 \mathrm{RS}$ translocations for their end-use quality defects, from the least to greatest effect as 1RS.1AL $<$ $1 \mathrm{RS} .1 \mathrm{BL}<1 \mathrm{RS} .1 \mathrm{DL}$. Previous studies on various wheat-rye translocation lines (William and MujeebKazi, 1993; Moreno-Sevilla et al., 1995b) also highlighted the importance of these chromosome arms for end-use quality.

Several different $1 \mathrm{RS}$ arms were studied in this experiment. These arms differ by their allelic composition at the Sec-1 locus (data not shown). While it was beyond the scope of this experiment to test the relative effects of different Sec-1 alleles, absence of clear differences suggests that there is little chance that utilizing different sources of $1 \mathrm{RS}$ could reduce the detrimental quality defects of the 1RS translocations. Graybosch et al. (1999) reached a similar conclusion in a study comparing end-use quality effects of two different $1 \mathrm{RS}$ arms present as $1 \mathrm{RS} .1 \mathrm{AL}$ translocations.

The overall quality effects of the introgression of the engineered chromosome 1R.1D $D_{5+10^{-}}$for $1 \mathrm{D}$ in Pavon 76 were similar to the effects of the substitutions of normal 1R. These included a reduction in GY, GVW, and $100-\mathrm{KW}$, an increase in the FP contents, and reduction in all quality parameters. However, while substitution of the same chromosome for $1 \mathrm{~A}$ also reduced agronomic performance, at the same time it improved MT 
and MTO relative to Pavon 76 and to other $1 \mathrm{R}(1 \mathrm{~A})$ substitutions. This indicates that increasing the dosage of the Glu-D1 locus (allele $d$ ) from two to four can compensate for the detrimental effects of the presence of $1 \mathrm{RS}$ in wheat.

By assembling a wide array of cytogenetic stocks and various constructs involving rye chromosome $1 \mathrm{R}$ in wheat, we attempted to systematically elucidate the role of rye chromatin in bread wheat. The use of ditelosomic lines and carefully constructed translocation lines with identical chromosomes and chromosome arms placed in various positions in the wheat genome discriminated between the effects of the introduction of rye chromatin into wheat and the effects of the concomitant removal of wheat chromatin. While some compensation for missing chromosome arms could not be eliminated, the data confirm many observations made in several previous studies (see Graybosch, 2001, for review), including the ranking of the relative contribution of the individual arms of wheat group 1 chromosomes to the end-use quality as well as the quality advantage of the $1 \mathrm{RS} .1 \mathrm{AL}$ translocation over 1RS.1BL. It also clearly identifies the quality defects associated with the 1RS arm (as opposed to the loss of the $1 \mathrm{~S}$ arms of wheat) and its interaction with the remaining two $1 \mathrm{~S}$ arms of wheat. It also demonstrates that, depending on their position in the wheat genome, some chromosome arms of rye can have beneficial effects on end-use quality, such as the $1 \mathrm{AS} .1 \mathrm{RL}$ e translocation tested here. It also establishes that from an agronomic point of view, translocation 1RS.1BL may be the best, while from the end-use quality point of view, 1RS.1AL translocation is the least detrimental. Its minimal quality defects can be compensated by extra doses of the Glu-D1 locus. In this experiment, the extra two doses of $G l u-D 1$ were introduced in an engineered $1 \mathrm{RL}$ which, similarly to all $1 \mathrm{RL}$ arms in wheat, has a negative impact on the agronomic performance. However, transfers of Glu-D1 to $1 \mathrm{~A}$ also exist (Lukaszewski and Curtis, 1992; Ceoloni et al., 1997) and could easily be combined with $1 \mathrm{RS}$ translocations to exploit the benefits of the presence of rye chromatin with less end-use quality penalties.

\section{REFERENCES}

AACC. 1995. Approved methods of the AACC. 9th ed. Am. Assoc. of Cereal Chemists, St. Paul, MN.

Braun, H.-J., T.S. Payne, A.I. Morgounov, M. van Ginkel, and S. Rajaram. 1998. The challenge: One billion tons of wheat by 2020 . p. 33-40. In A.E. Slinkard (ed.) Proc. 9th Int. Wheat Genet. Symp., Saskatoon, Canada. 2-7Aug. 1998. Univ. Ext. Press, Univ. of Saskatchewan, Saskatoon, SK, Canada.

Burnett, C.J., K.J. Lorenz, and B.F. Carver. 1995. Effect of the 1B/ $1 \mathrm{R}$ translocation in wheat on composition and properties of grain and flour. Euphytica 86:159-166.

Carver, B.F., and A.L. Rayburn. 1994. Comparison of related wheat stocks possessing 1B or 1BL.1RS chromosomes: Agronomic performance. Crop Sci. 34:1505-1510.

Carver, B.F., and A.L. Rayburn. 1995. Comparison of related wheat stocks possessing 1B or T1BL.1RS chromosomes: Grain and flour quality. Crop Sci. 35:1316-1321.

Ceoloni, C., F. Vitellozzi, P. Forte, F. Basili, M. Biagetti, A. Bitti, and V. Delre. 1997. Wheat chromosome engineering in the light of advanced genetic and cytogenetic marker-mediated approaches. p. 43-53. In T. Lelley (ed.) Current topics in plant cytogenetics related to plant improvement. WUV-Universitatsverlag, Vienna, Austria.

Dhaliwal, A.S., D.J. Mares, and D.R. Marshall. 1990. Measurement of dough surface stickiness associated with the 1B/1R chromosome translocation in bread wheats. Cereal Sci. 12:165-175.

Fritz, A.K., and R.G Sears. 1991. The effect of the Hamlet (2BS/2RL) translocation on yield components of hard red winter wheat. p. 94 In 1991 Agronomy abstracts. ASA, Madison, WI.

Graybosch, R.A. 1995. Compendium of wheat lines carrying rye chromosome arm 1RS [Online]. [47 p.] Available at: gopher://greengenes. cit.cornell.edu:70/00/.Quality/.Molecular/1rscom.prn [cited 2 Jan. 2003; verified 31 Mar. 2003]. Cornell Univ., Ithaca, NY.

Graybosch, R.A. 2001. Uneasy unions: Quality effects of rye chromatin transfers to wheat. J. Cereal Sci. 33:3-16.

Graybosch, R.A., J.H. Lee, C.J. Peterson, D.R. Porter, and O.K. Chung. 1999. Genetic, agronomic, and quality comparisons of two 1AL.1RS wheat-rye chromosomal translocations. Plant Breed. 118:125-130.

Graybosch, R.A., C.J. Peterson, L.E. Hansen, D. Worrall, D.R. Shelton, and A. Lukaszewski. 1993. Comparative flour quality and protein characteristics of $1 \mathrm{BL} / 1 \mathrm{RS}$, and $1 \mathrm{AL} / 1 \mathrm{RS}$ wheat-rye translocation lines. J. Cereal Sci. 17:95-106.

Gupta, R.B., K.W. Shepherd, and E. McRitchie. 1989. Effect of rye chromosome arm $2 \mathrm{RS}$ on flour protein and physical dough properties in bread wheat. J. Cereal Sci. 10:169-173.

Lee, J.H., R.A. Graybosch, and C.J. Peterson. 1995. Quality and biochemical effects of a 1RS. 1BL wheat-rye translocation in wheat. Theor. Appl. Genet. 90:105-112.

Lukaszewski, A.J. 1993. Reconstruction in wheat of complete chromosomes $1 \mathrm{~B}$ and $1 \mathrm{R}$ from the $1 \mathrm{RS} .1 \mathrm{BL}$ translocation of 'Kavkaz' origin. Genome 36:821-824.

Lukaszewski, A.J. 1997. Further manipulation by centric misdivision of the 1RS.1BL translocation in wheat. Euphytica 7:1-5.

Lukaszewski, A.J., and C.A. Curtis. 1992. Transfer of the Glu-D1 gene from chromosome $1 \mathrm{D}$ of breadwheat to chromosome $1 \mathrm{R}$ in hexaploid triticale. Plant Breed. 109:203-210.

McIntosh, R.A. 1984. A catalogue of gene symbols for wheat. p. 1197-1254. In S. Sakamoto (ed.) Proc. 6th Int. Wheat Genetic Symp., Kyoto, Japan. 28 Nov.-3 Dec. 1983. Plant Germplasm Inst., Kyoto Univ., Kyoto, Japan.

McKendry, A.L., D.N. Tague, and K.E. Miskin. 1996. Effect of 1BL.1RS on agronomic performance of soft red winter wheat. Crop Sci. 36:844-847.

Moreno-Sevilla, B., P.S. Baenziger, C.J. Peterson, R.A. Graybosch, and D.V. McVey. 1995a. The 1BL/1RS translocation: Agronomic performance of $\mathrm{F}_{3}$-derived lines from a winter wheat cross. Crop Sci. 35:1051-1055.

Moreno-Sevilla, B., P.S. Baenziger, D.R. Shelton, R.A. Graybosch, and C.J. Peterson. 1995b. Agronomic performance and end-use quality of $1 \mathrm{~B}$ vs. 1BL/1RS genotypes derived from winter wheat 'Rawhide'. Crop Sci. 35:1607-1612.

Rajaram, S., C.E. Mann, G. Ortiz-Ferrara, and A. Mujeeb-Kazi. 1984. Adaptation, stability and high yield potential of certain 1RS.1BL CIMMYT wheats. p. 613-621. In S. Sakamoto (ed.) Proc. 6th Int. Wheat Genetic Symp., Kyoto, Japan. 28 Nov.-3 Dec. 1983. Plant Germplasm Inst., Koyoto Univ., Koyoto, Japan.

Rogers, W.J., C.M. Rickatson, E.J. Sayers, and C.N. Law. 1990. Dosage effects of chromosomes of homoeologous group 1 and 6 upon bread-making quality in hexaploid wheat. Theor. Appl. Genet. 80:281-287.

SAS Institute. 1988a. SAS/STAT user's guide. Release 6.03. SAS Inst., Cary, NC.

SAS Institute. 1988b. SAS procedure guide. Release 6.03. SAS Inst., Cary, NC.

SAS Institute. 1992. SAS technical report, SAS/STAT software: Changes and enhancements. Release 6.07 ed. SAS Inst., Cary, NC.

Schlegel, R., and A. Meinel. 1994. A quantitative trait locus (QTL) on chromosome arm $1 \mathrm{RS}$ of rye and its effect on yield performance of hexaploid wheats. Cereal Res. Commun. 22:7-13.

Seo, Y.W., R.A. Graybosch, C.J. Peterson, and D.R. Shelton. 1995. 
Assessment of enzyme-linked immunoassay of rye secalins as a tool in the prediction of $1 \mathrm{RS}$ wheat quality. Cereal Chem. 72:252-254.

Shepherd, K.W., N.K. Singh, R.B. Gupta, and R.M.D. Koebner. 1992. Quality characteristics of flour from wheat-rye translocation and recombinant lines. p. 715-723. In W. Bushuk and R. Tkachuk (ed.) Gluten Proteins 1990. Am. Assoc. of Cereal Chemists, St. Paul, MN.

Singh, R.P., J. Huerta-Espino, S. Rajaram, and J. Crossa. 1998. Agronomic effects from chromosome translocations 7DL.7Ag and 1BL.1RS in spring wheat. Crop Sci. 38:27-33.

Villarreal, R.L., S. Rajaram, A. Mujeeb-Kazi, and E. Toro. 1991. The effect of chromosome 1RS.1BL translocation on the yield potential of certain spring wheat (Triticum aestivum L.). Plant Breed. 106: $77-81$.

William, M.D.H.M., and A. Mujeeb-Kazi. 1993. Rapid detection of $1 \mathrm{~B}, 1 \mathrm{BL} / 1 \mathrm{RS}$ heterozygotes in the development of homozygous 1BL/1RS translocation stocks of Triticum turgidum $(2 \mathrm{n}=4 \mathrm{x}=$ 28). Genome 36:1088-1091.

Zeller, F.J., and S.L.K. Hsam. 1984. Broadening the genetic variability of cultivated wheat by utilizing rye chromatin. p. 161-173. In S. Sakamoto (ed.) Proc. 6th Int. Wheat Genetic Symposium, Kyoto, Japan. 28 Nov.-3 Dec. 1983. Plant Germplasm Inst., Kyoto Univ., Kyoto, Japan. 